\title{
Cervical cancer: Disease prevention and informational support
}

by Lindsay Ashley Schwartz, RN, BScN

\section{Abstract}

Cervical cancer and Human Papillomavirus (HPV) are significant health care concerns for women worldwide. Globally, in 2006, cervical cancer remains the second most common cancer in women. Infection with highrisk strains of HPV is found to be present in approximately $99 \%$ of cervical cancer cases. The Supportive Care Framework developed by Fitch (2008) will serve as a guide to the paper. The need for informational support and disease prevention initiatives will be explored. Knowledge and awareness of HPV and its link to cervical cancer amongst the general population are low. Once women are made aware of the relationship between HPV and cervical cancer, they want more information on disease prevention, transmission, detection, treatment information, symptoms and risk for developing cancer. Evidence-based nursing interventions that focus on meeting the informational needs of women and increasing awareness of $H P V$ and cervical cancer will be proposed. Information on HPVprophylactic vaccines and Papanicolaou (PAP) screening as primary and secondary disease prevention strategies will be discussed.

This paper focuses on the significance of cervical cancer and its relationship to human papillomavirus (HPV). Guided by the Supportive Care Framework (Fitch, 2008), the purpose of this paper was to explore the informational needs of women in the general public concerning HPV and cervical cancer with the focus on disease prevention. The Supportive Care Framework (SCF) was originally developed by Fitch in 1994, as a conceptual tool for health care professionals to better understand the various needs of cancer patients and provide supportive care services. The version of the framework used for this paper was the version adapted for use in nursing curriculum by adding the nursing process (Logan, De Grasse, Stacey, Fiset, \& Fawcett, 1999), (see Figure One). Common themes noted in the literature concerning women's knowledge and attitudes towards cervical cancer, HPV and screening practices will be discussed. Evidence-based nursing interventions that focus on primary and secondary disease prevention strategies will be proposed. Disease prevention strategies will include widespread educational initiatives, as well as information on HPV prophylactic vaccines and Papanicolaou (PAP) screening.

\section{Significance of cervical cancer and HPV}

Cervical cancer is considered to be an extremely important health care issue and public health concern (Steven, Fitch, Dhaliwal, et al., 2004). Globally, cervical cancer remains the second most common cancer amongst women and resulted in more than 250,000 deaths in $2005,80 \%$ of those deaths occurred in developing countries (WHO, 2006). Canadian figures reveal that cervical cancer is currently the second most common cancer in women aged 20 to 44 (Canadian Cancer Society, 2006) and estimates of 1,300 new cases and 380 deaths will occur in 2008 (Canadian Cancer Statistics, 2008). Kaplan-Myrth and Dollin (2007) note that every week in Ontario, approximately 10 women are diagnosed with cervical cancer and three women will die from it.

The most common risk factors for developing cervical cancer are: a) early initiation of sexual intercourse, b) increased number of sexual partners, c) cigarette smoking, d) low socioeconomic status, e) Human immunodeficiency virus (HIV), f) infection with high-risk strains of

Lindsay Ashley Schwartz, RN, BScN, Sir Mortimer B.

Davis-Jewish General Hospital, Montreal, Quebec.

E-mail: lindsay.schwartz@mail.mcgill.ca
HPV, and g) prolonged use of oral-contraceptives (Garland \& Quinn, 2006; Tiffen \& Mahon, 2006), which are found to be present in approximately $99 \%$ of cervical cancer cases (Walboomers et al., 1999). Cervical cancer progresses slowly from dysplasic cells to invasive cervical cancer over a period of 10 to 15 years (Gerberding, 2004). Morrison (1994) suggests that five-year survival rates of cervical cancer are $90 \%$ in stage one and $10 \%$ to $15 \%$ in stage four. In many cases, cervical cancer is highly preventable and treatable through routine PAP screening and appropriate follow-up treatment (Gerberding, 2004).

HPV is considered to be one of the most prevalent sexually transmitted infections (STIs) around the world, and is common among both men and women (Friedman \& Shepeard, 2007; Tiffen \& Mahon, 2006). The lifetime risk of acquiring HPV is estimated to be as high as $75 \%$ (Koutsky, 1997). The majority of HPV infections are asymptomatic and transient without clinical consequences (Garland \& Quinn, 2006; Gerberding, 2004). However, a small portion of high-risk HPV infections persists to cause high-grade squamous intra-epithelial lesions and progress to the development of anogenital and cervical cancers (Giles \& Garland, 2006). High-risk HPV types 16 and 18 account for approximately $70 \%$ of cervical dysplasias and cervical cancer cases (Garland \& Quinn, 2006). Despite the high prevalence of HPV infection, knowledge and awareness of HPV amongst the general public in both the developed and developing world remains low (Moreira et al., 2006).

\section{Supportive care needs: Informational support}

Information needs and concerns regarding cancer are influenced by sociodemographic characteristics and phase in the cancer care continuum (Squiers, Finney Rutten, Treiman, Bright \& Hesse, 2005). Fitch (2000) notes that every patient requires information during the course of her illness and that information needs vary considerably throughout the cancer care continuum. Common information needs of clients include:

\section{Cancer du col utérin : prévention de la maladie et soutien informationnel}

\section{Abrégé}

Le cancer du col utérin et le virus du papillome humain (VPH), ou papillomavirus, constituent, pour les femmes du monde entier, de graves préoccupations en matière de santé. À l'échelle mondiale, le cancer du col utérin demeurait, en 2006, le deuxième plus fréquent des cancers chez les femmes. La présence d'une infection par des souches de VPH à haut risque est constatée dans environ $99 \%$ des cas de cancer du col utérin. Le Cadre des soins de soutien conçu par Fitch (2008) guidera l'élaboration du présent article. On explorera la nécessité d'avoir des initiatives de soutien informationnel et de prévention de la maladie. Le grand public connaît peu le papillomavirus, ses liens avec le cancer du col utérin et y est peu sensibilisé. Pourtant, une fois que les femmes prennent conscience de la relation entre le papillomavirus et le cancer du col utérin, elles veulent disposer de davantage d'information sur la prévention de la maladie, sa transmission, sa détection et son traitement, sur les symptômes et sur les risques de développer le cancer. On proposera des interventions infirmières basées sur des données probantes qui visent à satisfaire les besoins d'information des femmes et à accroître leur sensibilisation au papillomavirus et au cancer du col. On discutera des informations sur les vaccins prophylactiques contre le VPH et le dépistage au moyen du test de Papanicolaou comme stratégies de prévention primaire et secondaire de la maladie.

La traduction de cette article est sur la site Web de l'ACIO. 
a) information about cancer, b) symptoms, c) cancer-related procedures and treatments, d) available services, and e) information on cancer screening and prevention strategies (Fitch, 2000; Squiers et al., 2005). These findings closely reflect the information needs found in the literature regarding HPV and cervical cancer prevention noted below.

\section{Desired Information}

Friedman and Shepeard (2007) suggest that once women are informed about the nature of HPV, they want more information pertaining to: a) the signs and symptoms, b) prevalence, c) transmission, d) prevention, e) treatment, f) detection, g) curability of the infection, h) a list of organizations and resources to contact for more information, and i) information about where they can receive screening. Similar to the findings of Friedman and Shepeard, and Anhang, Goodman and Goldie (2004) note that women want specific health care information focusing on: a) transmission, b) prevention, c) detection, d) treatment and progression without treatment, and e) their own personal risks for acquiring HPV and cervical cancer. Additionally, women want information about the typical duration of HPV infection, the likelihood of developing cancer (Anhang, Goodman \& Goldie) and information on HPV prophylactic vaccines (Tiro, Meissner, Kobrin, \& Chollette, 2007).

Lack of knowledge: HPV and cervical cancer: Awareness of HPV has increased over the past decade. However, knowledge of its link to cervical cancer remains low. A national survey of American women aged 18 to 75 in 2005 indicates that only $40 \%$ of study participants have heard of HPV and only half of those participants knew that it could cause cervical cancer (Tiro et al., 2007). Many women are unaware of the risk factors associated with HPV infection, the clinical problems it may cause and its potential long-term cause of cervical cancer (Garland, 2006; Garland \& Quinn, 2006; Tiro et al., 2007). A survey of female students at an American university revealed that the majority of the students who responded were unaware that HPV can cause cervical cancer, that the infection may be asymptomatic, unfamiliar with the modes of transmission, unaware that PAP screening may detect dysplasic cells and did not believe they were susceptible for acquiring HPV (Yacobi, Tennant, Ferrante, Pal, \& Roetzheim, 1999).

Factors contributing to the public's need for information: Insufficient and misleading information concerning HPV and cervical cancer are contributing factors to the information needs of the public (Garland \& Quinn, 2006). Anhang, Goodman and Goldie (2004) suggest that women's main sources of health care information include health care providers, friends, family, health education classes, the internet and the media. The authors propose that information about HPV can vary across women's sources for information, contributing to information gaps, confusion and lack of credible information. Furthermore, the news

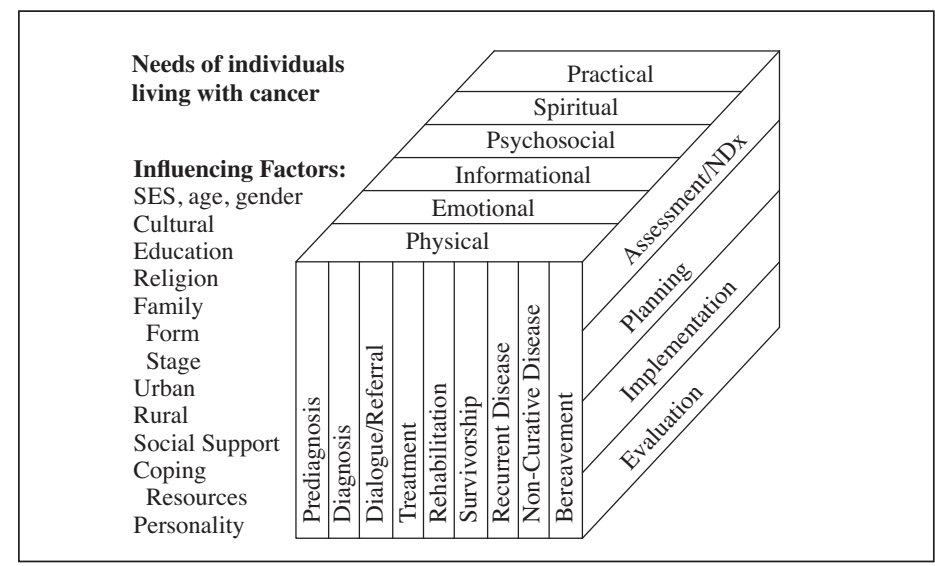

Figure One: Supportive care framework from the article by Logan, J., De Grasse, C.E., Stacey, D., Fiset, V., \& Fawcett, L. (1999). Reprinted with permission from the Canadian Oncology Nursing Journal. media coverage on HPV can be incomplete, inaccurate and sometimes misleading (Anhang, Stryker, Wright, \& Goldie, 2004). Tristram (2006) notes that HPV information conveyed by the media may cause increased anxiety and STI-related stigmas, contributing to poor screening practices.

\section{Phases in continuum of care: Disease prevention}

Disease prevention strategies may target the general population, sub-populations or populations identified as being at risk (Shakeshaft \& Frankish, 2003). Furthermore, prevention strategies can be categorized along a continuum, starting with primary levels of prevention to tertiary levels of prevention (Shakeshaft \& Frankish, 2003). Primary prevention initiatives attempt to prevent disease occurrence and may include: public education programs, prophylactic vaccination, and legislative approaches (Shakeshaft \& Frankish, 2003). Secondary prevention initiatives, including screening practices aim to detect cancer early in the asymptomatic stages of disease (Mahon, 2003).

\section{Nurses' role in disease prevention}

Nurses at all levels can be leaders in disease prevention initiatives. Tiffen and Mahon (2006) suggests that nurses can advocate for their patients by connecting them to community-based educational resources and health services. Nurse practitioners can be health teachers and provide information about HPV and review current screening options with women (Anhang, Goodman, \& Goldie, 2004). Nurse researchers can address the compliance and cost-effectiveness of community screening programs (Steven et al., 2004). Nurses can also work in collaboration with gynecologists and family practitioners in developing effective and efficient cervical cancer screening programs (Steven et al., 2004). Nurses must work in partnership with community representatives such as key health policymakers and stakeholders to improve women's access to screening services (Steven et al., 2004). Cervical cytology screening programs are available in developed countries and screening services have been initiated in some developing countries, predominantly in South and Central America (Sankaranarayanan, Budukh, \& Rajkumar, 2001).

Incidentally, cytology screening has had minimal impact on the incidence of cervical cancer in developing countries resulting from the absence of formalized screening programs, poor quality testing, inadequate testing practices and unequal distribution of screening throughout the population (Sankaranarayanan, Budukh, \& Rajkumar, 2001).

Primary disease prevention: HPV prophylactic vaccines: Widespread educational programs that increase awareness of HPV and its link to cervical cancer will be necessary in promoting the public's acceptance and interest in receiving the newly introduced HPV prophylactic vaccines Cervarix ${ }^{\circledR}$ and Gardasil ${ }^{\circledR}$. Gerend, Cruz Lee and Shepherd (2007) recommend providing individuals with information on the preventative effects that the vaccine will have on HPV and cervical cancer prior to assessing their interest in obtaining the vaccine. Greater interest in receiving HPV vaccination is associated with individuals who perceive themselves as being at risk for HPV and cervical cancer, who perceive the vaccine as being safe and effective and who are encouraged to receive the vaccine by a health care professional (HCP) (Giles \& Garland, 2006; Gerend et al., 2007). It is predicted that HCPs will play a major role in promoting vaccine acceptance by providing patient education and support (Gerend et al., 2007; Sherris et al., 2006).

The Gardasil ${ }^{\circledR}$ vaccine is approved by the Food and Drug Administration (FDA) and its use is accepted for females aged 9 to 26 (Friedman \& Shepeard, 2007; Gerend et al., 2007). The vaccine protects against HPV types: 6, 11, 16 and 18, all responsible for $70 \%$ of invasive cervical cancers and $90 \%$ of anogenital warts (Friedman \& Shepeard, 2007). Given the fact that the vaccine does not provide complete immunity and that the length of immunity is unknown, educating women about their need to continue participating in screening programs and protective sexual practices is necessary (Friedman \& Shepeard, 
2007). Prophylactic HPV vaccination for boys and young men has not yet been approved and will depend mainly on efficacy and costeffectiveness (Fisher, Darrow, Tranter, \& Williams, 2008).

Secondary disease prevention: PAP screening: Brisson, Van de Velde, De Wals and Boily (2007) note "screening programs have substantially reduced the incidence and mortality of cervical cancer over the past 50 years. However, the marked declines seen until the 1990s have been slowing in recent years" (p. 5399). A paucity of PAP screening amongst women has been identified as the single most contributing factor to the development of invasive cervical cancer (Sawaya \& Washington, 1999). Nuovo, Melnikow and Howell (2001) suggest that $50 \%$ of women diagnosed with cervical cancer have never received a PAP test and $10 \%$ have not received the test within the past five years. The Canadian Task Force on Preventive Health Care (CTFPHC) suggests that women who have never received PAP screening are at highest risk for dying from cervical cancer, and notes that women living in Canada least likely to be screened are those over 50, native women, and women who have immigrated from poorer countries (cited in Morrison, 1994).

The Ontario Cervical Screening Practice Guidelines (2005) recommend that women initiate PAP screening once they become sexually active and continue annual screening until they have three consecutive negative PAP test results. Screening is then recommended every two to three years and may be discontinued after 70 years of age, providing there is a minimum of three negative PAP tests in the past 10 years (Cancer Care Ontario, 2005). The CTFPHC (cited in Morrison, 1994) suggests that there is fair evidence to include PAP screening in women's periodic health exams and classifies PAP screening as a B recommendation. Conventional PAP tests have a sensitivity rate greater than $77 \%$ in detecting high-grade squamous intraepithelial lesions (Andy \& Turner, 2004). The majority of health care organizations recommends initial PAP screening before the age of 21 or within three years after the onset of sexual intercourse, followed by maintenance screening every one to three years up to the age of 65 if previous results were normal (Tiffen \& Mahon, 2006).

Poor knowledge, lack of access to screening facilities, anxiety, fear and embarrassment are consistent barriers to cervical cancer screening (Garland \& Quinn, 2006; Wheeler, 2007). Furthermore, Steven et al. (2004) note the following deterrents to cervical cancer screening: cultural beliefs, negative experiences with the test, discomfort during the procedure and feeling that the test is an invasion of privacy. Poor knowledge concerning the purpose and preventative potential of screening, as well not understanding test results or being unaware of recommended screening intervals are additional factors contributing to suboptimal screening practices by women (Rydstrom \& Tornberg, 2006). Nurses can promote long-term adherence to screening programs by reminding women when they are due for screening by sending postcards and telephone reminders (Steven et al., 2004). Clear health information about PAP tests such as step-by-step information of the procedure and its purpose are other effective interventions aimed at increasing screening compliance (Steven et al., 2004). Nursing efforts that focus on overcoming barriers to PAP screening will significantly contribute to the health and well-being of women.

\section{Evidence-based nursing interventions: Increasing awareness and information support}

Friedman and Shepeard (2007) suggest that nursing interventions aimed at increasing awareness of HPV and cervical cancer amongst women in the general public should take a public health approach to health education. HPV and cervical cancer communications need to be framed as a universal health concern rather than as a STI-related cause, which may be stigmatizing (Friedman \& Shepeard, 2007). Furthermore, population-based educational initiatives may motivate women to participate in preventative health efforts, engage in risk- reduction behaviours and attend recommended screening programs (Moreira et al., 2006; Tristram, 2006).

Health education can be delivered in a variety of clinical and community settings. Opportunities to educate the public about HPV immunization and screening practices can occur during sexual education classes in school, health fairs, in community clinics and during standard health and physical exams (Tiffen \& Mahon, 2006). Nursing strategies in clinical practice can address HPV, prophylactic vaccination and cervical cancer screening in young women as part of the nursing assessment regardless of their diagnosis. Nurses must also target the hard-to-reach populations such as immigrants, low-income citizens and people living in rural areas (Anhang, Goodman, \& Goldie, 2004). Garland and Quinn (2006) note that men are often neglected in the delivery of HPV information and suggest the importance of educating both young males and females about sexual health and use of protective mechanisms. As males and females have different learning styles and particular interests in sexual education topics, they may benefit from separation in sexual health education for some time to tailor genderspecific sexual education needs and interests (Hilton, 2001).

In delivering health care programs, nurses must first assess priority learning needs and concerns of the population of interest. For information to reach the public and promote healthy lifestyle behaviours, information needs to be relevant and meaningful (Friedman \& Shepeard, 2007). Nurses must also assess the learners' preferred learning styles and knowledge, attitudes and beliefs of the health care topic. Steven et al. (2004) suggest that HCPs must also provide culturally-sensitive education and care.

As health care teachers, nurses must also provide clear, current, simple and accurate information that meets the public's information needs. The public needs accurate information about HPV and cervical cancer if they are to make informed health care decisions regarding HPV immunization, screening practices and risk-reduction behaviours (Friedman \& Shepeard, 2007). Tristram (2006) suggests that accurate information on HPV and cervical cancer is needed to overcome misconceptions, stigmas and misinformation held by some members of society. Nurses must "normalize" HPV communications and overcome the sexual-promiscuity stigmas. De-stigmatizing HPV infection can increase screening compliance and acceptance of HPV prophylactic vaccines (Friedman \& Shepeard, 2007; Tiro et al., 2007).

Steven et al. (2004) note that nurses can use a variety of sources to increase awareness of HPV and cervical cancer prevention by providing information through booklets, magazine and newspaper articles, as well as through the media. Tristram (2006) notes that the internet and media are common health care informational sources used by women. Nurses can also collaborate with pharmaceutical companies to ensure their information pamphlets and public communications provide clear health information that is appropriate for their target audiences. Nurses can provide clients with relevant evidence-based internet sites and resources, and help disseminate factual information regarding HPV, cervical cancer, screening and immunization practices through the media (Tristram, 2006).

Cervical cancer and HPV are extremely important health care concerns that affect women worldwide. The public's knowledge and awareness of HPV, cervical cancer and their relationship is low. Accurate and reliable health care information is needed to meet the informational needs of the population and promote informed health care decisions and healthy lifestyle practices. Nurses play an active role in disease prevention and are a trusted source of health care information and advice amongst women (Garland, 2006). Informing the population about HPV and its link to cervical cancer, as well as the preventative effects of screening and HPV immunization are important prerequisites in the fight against cervical cancer in women worldwide.

\section{Acknowledgement}

The author gratefully acknowledges Dawn Stacey, RN, MScN, PhD, at the University of Ottawa for her support and guidance in the development of the paper. 


\section{References}

Andy, C., \& Turner, L.F. (2004). Is the ThinPrep better than conventional Pap smear at detecting cervical cancer? Journal of Family Practice, 53(4), 313-316.

Anhang, R., Goodman, A., \& Goldie, S.J. (2004). HPV communication: Review of existing research and recommendations for patient education. A Cancer Journal for Clinicians, 54(5), 248-259.

Anhang, R., Stryker, J.E., Wright, T.C, Jr., \& Goldie, S.J. (2004). News media coverage of human papillomavirus. Cancer, 100(2), 308-314.

Brisson, M., Van de Velde, N., De Wals, P., \& Boily, M.C. (2007). The potential cost-effectiveness of prophylactic human papillomavirus vaccines in Canada. Vaccine, 25, 5399-5408.

Canadian Cancer Society. (2006). Cancer in young adults in Canada. Retrieved December 5, 2008, from http://www.cancer.ca

Canadian Cancer Society. (2008). Canadian Cancer Statistics. Retrieved December 5, 2008, from: http://www.cancer.ca

Cancer Care Ontario. (2005). Ontario Cervical Screening Practice Guidelines. Retrieved March 28, 2008, from http://www.cancercare.on.ca/documents/CervicalScreening Guidelines.pdf

Fisher, R., Darrow, D., Tranter, M., \& Williams, J. (2008). Human papillomavirus vaccine: Recommendations, issues and controversies. Current Opinion in Pediatrics, 20(4), 441-445.

Fitch, M. (1994). Providing Supportive Care for Individuals Living With Cancer: Report of the Ontario Cancer Treatment and Research Foundation (OCTRF). Toronto: OCTRF.

Fitch, M. (2000). Supportive care for cancer patients. Hospital Quarterly, 3(4), 39-46.

Fitch, M. (2008). Supportive Care Framework. Canadian Oncology Nursing Journal, 18(1), 6-14.

Friedman, A.L., \& Shepeard, H. (2007). Exploring the knowledge, attitudes, beliefs and communication preferences of the general public regarding HPV: Findings from CDC focus group research and implications for practice. Health Education \& Behavior, 34(3), 471-485.

Garland, S.M. (2006). Human papillomavirus vaccines: Challenges to implementation. Sexual Health, 3, 63-65.

Garland, S.M., \& Quinn, M.A. (2006). How to manage and communicate with patients about HPV? International Journal of Gynecology and Obstetrics, 94(1), 106-112.

Gerberding, J.L. (2004, January). Report to Congress: Prevention of genital human papillomavirus infection. Atlanta, GA: Centers for Disease Control and Prevention, Department of Health and Human Services.

Gerend, M.A., Cruz Lee, S., \& Shepherd, J.E. (2007). Predictors of human papillomavirus vaccination acceptability among underserved women. Sexually Transmitted Diseases, 34(7), 466-471.

Giles, M., \& Garland, S. (2006). A study of women's knowledge regarding human papillomavirus infection, cervical cancer and human papillomavirus vaccines. Australian and New Zealand Journal of Obstetrics and Gynecology, 46, 311-315.

Hilton, G.L.S. (2001). Sex education - The issues when working with boys. Sex Education, 1(1), 31-41.

Kaplan-Myrth, N., \& Dollin, J. (2007). Cervical cancer awareness and HPV prevention in Canada. Canadian Family Physician, 53, 693-697.

Koutsky, L. (1997). Epidemiology of genital human papillomavirus infection. American Journal of Medicine, 102(5A), 3-8.

Logan, J., De Grasse, C.E., Stacey, D., Fiset, V., \& Fawcett, L. (1999). Oncology nursing education within a supportive care framework: An evidence-based undergraduate course. Canadian Oncology Nursing Journal, 9(2), 64-66.

Mahon, S.M. (2003). Skin cancer prevention: Education and public health issues. Seminars in Oncology Nursing, 19(1), 52-61.
Moreira, E.D., Oliveira, B.G., Ferraz, F.M., Costa, S., Costa Filho, J.O., \& Karic, G. (2006). Knowledge and attitudes about human papillomavirus, pap smears, and cervical cancer among young women in Brazil: Implications for health education and prevention. International Journal of Gynecological Cancer, 16, 599-603.

Morrison, J.B. (1994). Screening for cervical cancer. Retrieved October 30, 2007, from the Canadian Task Force on Preventive Health Care, http: www.ctfphc.org/Full_Text_printable/ Ch73full.htm

Nuovo, J., Melnikow, J., \& Howell, L.P. (2001). New tests for cervical cancer screening. American Family Physician, 64(5), 780-786.

Rydstrom, G., \& Tornberg, S. (2006). Cervical cancer incidence and mortality in the best and worst of worlds. Scandinavian Journal of Public Health, 34, 295-303.

Sankaranarayanan, R., Budukh, A.M., \& Rajkumar, R. (2001). Effective screening programs for cervical cancer in low- and middle-income developing countries. Bulletin of the World Health Organization, 79(10), 954-962.

Sawaya, G., \& Washington, E.A. (1999). Cervical cancer screening: Which techniques should be used and why? Clinical obstetrics and gynecology, 42(4), 922-938.

Shakeshaft, A.P., \& Frankish, J.C. (2003). Using patient-driven computers to provide cost-effective prevention in primary care: A conceptual framework. Health Promotion International, 18(1), $67-77$.

Sherris, J., Friedman, A., Wittet, S., Davies, P., Steben, M., \& Saraiya, M. (2006). Education, training, and communication for HPV vaccines. Vaccine, 24, 210-218.

Squiers, L., Finney Rutten, L.J., Treiman, K., Bright, M.A., \& Hesse, B. (2005). Cancer patients' information needs across the cancer care continuum: Evidence from the cancer information services. Journal of Health Communication, 10(1), 15-34

Steven, D., Fitch, M., Dhaliwal, H., Kirk-Gardner, R., Sevean, P., Jamieson, J., et al. (2004). Knowledge, attitudes, beliefs and practices regarding breast and cervical cancer screening in selected ethnocultural groups in northwestern Ontario. Oncology Nursing Forum, 31(2), 305-311.

Tiffen, J., \& Mahon, S.M. (2006). Cervical cancer: What should we tell women about screening? Clinical Journal of Oncology Nursing, 10(4), 527-531.

Tiro, J.A., Meissner, H.I., Kobrin, S., \& Chollette, V. (2007). What do women in the U.S. know about human papillomavirus and cervical cancer? Cancer Epidemiology, Biomarkers \& Prevention, 16(2), 288-294.

Tristram, A. (2006). HPV information needs. Best Practice \& Research, 20(2), 267-277.

Walboomers, J.M., Jacobs, M.V., Manos, M.M., Bosch, F.X., Kummer, J.A., Shah, K.V., et al. (1999). Human papillomavirus is a necessary cause of invasive cervical cancer worldwide. Journal of Pathology, 189(1), 12-19.

Wheeler, C.M. (2007). Advances in primary and secondary interventions for cervical cancer: Human papillomavirus prophylactic vaccines and testing. Nature Clinical Practice Oncology, 4(4), 224-235.

World Health Organization. (2006). Comprehensive cervical cancer control: A guide to essential practice. Retrieved December 5, 2008, from http://www.who.int/reproductive-health/publications/ cervical_cancer_gep/text.pdf

Yacobi, E., Tennant, C., Ferrante, J., Pal, N., \& Roetzheim, R. (1999). University Students' knowledge and awareness of HPV. Preventive Medicine, 28, 535-541. 